\title{
Evaluating the roll-out of environmental control units in Veterans Affairs Spinal Cord Injury Centers: Workflow observations
}

\author{
Balmatee Bidassie*1, Marissa A. Vallette ${ }^{1}$, Theadora James ${ }^{1}$, Rachael Martinez ${ }^{2}$, Bella Etingen ${ }^{2}$, Huberta Cozart ${ }^{3,4}$, \\ Frances M. Weaver ${ }^{2,5}$ \\ ${ }^{1}$ Veterans Affairs - Center for Applied Systems Engineering (VA-CASE), Clinical Partnerships in Healthcare Transformation \\ (CPHT), Veterans Engineering Resource Center (VERC), Indianapolis, IN, United States \\ ${ }^{2}$ Center of Innovation for Complex Chronic Healthcare (CINCCH), Health Services Research \& Development, Department of \\ Veterans Affairs, Hines VA Hospital, Hines, IL, United States \\ ${ }^{3}$ Spinal Cord Injury Care Line, Michael E. DeBakey VA Medical Center, Houston, TX, United States \\ ${ }^{4}$ Department of Physical Medicine \& Rehabilitation, Baylor College of Medicine, Houston, TX, United States \\ ${ }^{5}$ Department of Public Health Sciences, Stritch School of Medicine, Loyola University, Maywood, IL, United States
}

Received: May 11, 2017

DOI: $10.5430 /$ ijh.v3n2p57
Accepted: July 21, 2017

URL: https://doi.org/10.5430/ijh.v3n2p57
Online Published: August 15, 2017

\begin{abstract}
Objective: Evaluate the value of providing environmental control units (ECUs) to Veterans with spinal cord injuries and/or disorders (SCI/D) in Veterans Affairs Medical Centers (VAMCs).

Design: Industrial engineers observed SCI/D staff (support) and Veterans (use) with ECUs at four participating VAMC Spinal Cord Injury (SCI) Centers.

Measure(s)/Analysis: Standardized data collection efforts included: 1) time study (trend analysis) and 2) open-ended, semistructured interviews on Strengths-Weaknesses-Opportunities-Threats (SWOT) feedback (qualitative analysis).

Results: From 59 interactions, reasons for ECU downtime were troubleshooting $(n=30,51 \%)$, repairs/replacements $(n=10$, $17 \%)$, and $29 \%$ combined for patient education $(n=8)$, set-up $(n=5)$, and admission $(n=4)$. ECU strengths were functionality ( $=23,70 \%)$ and $30 \%(n=10)$ combined for patient independence and staff satisfaction. Functionality was both a weakness $(n=$ $43,78 \%)$ and opportunity $(n=29,66 \%)$. Threats were functionality $(n=8,50 \%)$, staff satisfaction $(n=3,19 \%)$, and maintenance $(\mathrm{n}=5,31 \%)$. When ECUs were functioning properly, Veterans participated in leisurely activities (e.g., games, television), had increased control of their environment (e.g., bed, lights), and clinicians spent less time troubleshooting the ECU, hence, increasing clinical care availability.

Conclusions: ECUs minimized physical limitation challenges, and may improve safety, comfort level, and general satisfaction with care of Veterans with SCI/D who often spend much of their time in bed when hospitalized. Veterans and staff reported that the ECUs added value by increasing patient independence and social support including communication with loved ones. Functionality strengths and weaknesses influenced the Veterans'/staff's perceptions of ECU value. Therefore, ECU training/maintenance education and dedicated non-clinical support staff are recommended prior to future ECU roll-out.
\end{abstract}

Key Words: Patient-independence, Patient-satisfaction, Efficiency-workflow, Functionality, Human factors, Sustainability

*Correspondence: Balmatee Bidassie; Email: balmateeb@gmail.com; Address: Veterans Affairs - Center for Applied Systems Engineering (VA-CASE), Clinical Partnerships in Healthcare Transformation (CPHT), Veterans Engineering Resource Center (VERC), Indianapolis, IN, United States. 


\section{INTRODUCTION}

Individuals with spinal cord injuries and disorders (SCI/D) of ten spend much of their time in bed when hospitalized. Based on the level of paralysis, their independence and participation in activities are limited to some degree. Environmental control units (ECUs) are devices that allow individuals who have functional limitations and/or disabilities (such as persons with SCI/D) to increase their independence to control aspects of their environment. Many types of ECUs are commercially available. In a hospital setting, increased patient independence may increase the availability of nurses and other clinical staff to provide clinical care and may also improve patient safety by allowing patients to easily call the nursing staff for assistance. ECUs tend to improve the level of a patient's comfort during their hospital stay and increase their general satisfaction with care. ${ }^{[1]}$ Figure 1 provides a photograph of an ECU and a description of some of its features.
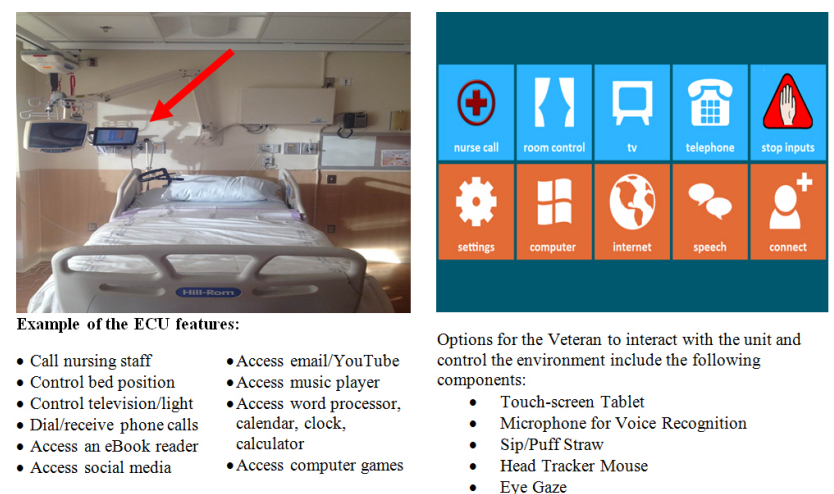

Options for the Veteran to interact with the unit and control the environment include the following components:

- Touch-screen Tablet

- Microphone for Voice Recognition

- Sip/Puff Straw

- Head Tracker Mouse

Figure 1. An example of an ECU

Within the Veterans Health Administration (VHA), there are 24 inpatient units (i.e., Spinal Cord Injury (SCI) Centers) ${ }^{[2]}$ that provide care for over 26,000 Veterans with SCI/D..$^{[3,4]}$ Hospitalized Veterans with SCI/D are challenged to control their surroundings due to limited mobility. ${ }^{[5]}$ Consequently, nurses and staff often spend a significant amount of time assisting these patients with basic functions which limits their time to provide clinical care. ${ }^{[6,7]}$ To provide better care to and optimize the experience with inpatient care for Veterans with SCI/D, Veterans Affairs Medical Centers (VAMCs) are exploring the value of implementing ECUs in SCI Centers. Feedback from this study may influence future roll-outs of ECUs to other SCI Centers.

This manuscript highlights results from an approved quality improvement (QI) effort to facilitate implementation of ECUs across selected VAMCs. Engineers evaluated functional capabilities of ECUs based on feedback from 1) Veterans' (i.e., patients') usage to gain insight from the Veteran's perspective, 2) staff's perspectives and feedback, and 3) time study analyses to understand resources and time required to complete tasks related to the ECU. Future studies will be able to use these QI insights to implement Plan-Do-Study-Act (PDSA) cycles $^{[8,9]}$ for future VAMC facility ECU roll-outs. This study was conducted in collaboration with the Center of Innovation for Complex Chronic Healthcare (CINCCH) located at the Edward Hines, Jr., Veterans Administration Hospital and Veterans Affairs-Center for Applied Systems Engineering (VA-CASE) Veterans Engineering Resource Center (VERC) Clinical Partnerships in Healthcare Transformation (CPHT) program. This evaluation aligns with the VA mission to "honor America's Veterans by providing exceptional health care that improves their health and well-being" ${ }^{[10]}$ and strive to have a Veteran-centered culture.

\section{Methods}

Four VAMCs with SCI Centers that included inpatient and long-term care beds for Veterans with SCI/D were identified and invited to participate in a QI initiative (IRB approval not required) to evaluate the roll-out of ECUs in SCI Centers. These four sites were among the first to have ECUs implemented in their facilities and were willing to participate in this study. Three sites used one type of ECU and the fourth used a different ECU; however, the goal of this study was not to evaluate any specific ECU brand but rather to evaluate the value of the ECU in general for Veterans and staff. Staff members and Veterans who had some level of interaction with the ECUs were included. Staff members were: nurses, nursing assistants, physicians, biomedical engineers, physical therapists, occupational therapists, patient advocates, volunteer services, and environmental management services.

One or two VA-CASE CPHT industrial engineers (IEs) visited each facility for five days from August 2015 - October 2015. The IEs observed facility staff as they interacted with Veterans and the ECUs. IEs conducted time studies to track the Veteran and staff interaction time with the ECU, the time wasted, or the reason why the ECU was not in use. Accurately capturing time estimates and developing standards of work can help increase workflow efficiency and functionality by reducing/eliminating non-value-added activities while providing high quality care in a healthcare system. ${ }^{[1]}$

Strengths-Weaknesses-Opportunities-Threats (SWOT) analysis $^{[12,13]}$ is a QI tool used in studies throughout the world $^{[12,14-18]}$ to inform improvement efforts in a variety of healthcare settings and populations such as traumatic brain injury, ${ }^{[14]}$ pediatric rehabilitation, ${ }^{[15]}$ community health, ${ }^{[16]}$ oral healthcare, ${ }^{[17]}$ and geriatric care in the military. ${ }^{[19]}$ In our study, facility staff and Veterans' perspectives were col- 
lected to determine the strengths and weaknesses of the ECUs as well as their opportunities and threats. ${ }^{[14]}$ SWOT analysis results provided insight on facility staff and Veterans' overall satisfaction with the ECU and resulting patient independence.

\subsection{Data collection}

Standardized templates were developed to capture data for both time studies (see Table 1) and SWOT analyses (see Table 2). The IEs observed all interactions by facility staff and Veterans with the ECUs. Time studies were completed by using a stopwatch, clipboard, and a template/form to cap- ture relevant details of the work being observed ${ }^{[20]}$ as well as documenting all non-value-added activities (waste) observed. ${ }^{[21,22]}$ The eight wastes in healthcare ${ }^{[11]}$ examined were: defects, overproduction, waiting, not utilizing human potential, transportation, inventory, motion, and excess processing. ${ }^{[21]}$ The SWOT analysis feedback was voluntary and data were collected face-to-face. The IE(s) read a list of standardized, open-ended questions to each participating facility staff and patient. All responses were captured electronically. The definitions for strengths, weaknesses, opportunities, and threats for this study were based on those as described by Gordon and colleagues. ${ }^{[12]}$

Table 1. Detailed list of data collected for time study analysis
a) Veteran identifier: The unique combination assigned to each Veteran in the observation process.
b) Age: The numerical age of the Veteran being observed.
c) Type of injury: The injury diagnosis of the Veteran being observed.
- Tetraplegic: A spinal cord injury sustained above the first thoracic vertebra results in tetraplegia. A tetraplegic has paralysis to some degree in all four limbs.
- $\quad$ Paraplegic: A spinal cord injury that occurs below the first thoracic spinal nerve results in paraplegia. A paraplegic can move their arms and hands.
d) Description of Process/Task:
i. Admission: Patient admittance to a short-term or long-term care SCI unit. Also included initial patient education of the ECU.
ii. Patient Education: Patient received education on the ECU from a clinical staff member or member of the SCI unit.
iii. Repair: Some level of repair was needed in order for the ECU to function properly. Repairs could usually be resolved within the same day.
iv. Replacement: Replacement of an ECU or parts was needed when simple repairs could not fix the ECU. This process typically took more time than repairs to resolve.
v. Set-Up: The customization of an ECU based on patient needs, injury diagnosis, and mobility.
vi. Troubleshooting: The systematic search for the source of a problem in order to solve it. Troubleshooting typically occurred prior to repairs and replacements; however, repairs and replacements were not always necessary. For example, an unplugged cord may have been the solution to a problem.

vii. Work Order Request: The process that was completed when ordering additional supplies that were not in the facility inventory.

e) Person Completing Process/Task: The title of the person completing the process listed above. The industrial engineers would directly ask this person his/her title.

Biomedical Engineer

Nurse/Nursing Assistant

Patient Experience Liaison/Volunteer: Either Patient Experience Liaison or Volunteer was used to describe an individual in this non-clinical role and was site-dependent.

f) Start: The time recorded at the beginning of a process/task.

g) Stop: The time recorded when a process/task was completed.

h) Elapsed Time: The difference in time when a process was completed and the time a process began. (Stop - Start $=$ Elapsed Time)

i) Waste Observed (reason for the ECU not being used):

- $\quad$ Defects: Mistakes that require additional time, resources, or money to fix.

- $\quad$ Overproduction: Redundancy; producing more than necessary.

- Waiting: Idle time; any time patients or products were waiting for something.

- $\quad$ Not Utilizing Human Potential: Not using peoples’ mental, creative, and physical abilities in the best way to create value.

- Transportation: Required relocation/delivery of patient, materials, equipment, or supplies to complete a task.

- Inventory: Stock on hand; more materials ordered than required to complete the work.

- Motion: Movement of people that does not add value; the time spent walking from one location to another.

- Excessive Processing: Additional processing steps that do not add value from the Veteran or staff perspective.

j) Priority: The process of determining the overall importance of correcting the waste observed.
a. High: Essential to correct identified waste in order for process to flow and ECU to function appropriately.
b. Medium: Important to correct identified waste but does not hinder the complete process flow.
c. Low: Waste has been observed but it does not have a negative impact on the process flow.

k) Expected Ease to Correct: The time and resources required to eliminate the identified waste. Expected ease to correct was determined using the three categories listed below:

a. Hard: Long delays and the need for additional resources will be required in order to eliminate waste.

b. Medium: Long delays or additional resources will be required in order to eliminate waste.

c. Easy: Waste will be corrected in a short time with little to no resources. 
Table 2. Standardized questionnaire used in the SWOT analysis

\begin{tabular}{|c|c|}
\hline \multicolumn{2}{|l|}{ Clinician } \\
\hline $\begin{array}{l}\text { Strengths } \\
\text { - What advantages do ECU devices bring to the facility? } \\
\text { - What benefits do ECUs provide the patient? } \\
\text { - How much time, if any, do you spend educating patients on ECUs? } \\
\text { - How does patient customization affect the use of the device? } \\
\text { - Are there any additional strengths you wish to identify regarding the } \\
\text { ECU device? }\end{array}$ & $\begin{array}{l}\text { Opportunities } \\
\text { - How could the ECU be further improved? } \\
\text { - What interesting trends (patient satisfaction, impact on cost, etc.) are you aware of? } \\
\text { - How can the training on ECUs be improved? } \\
\text { - Wi-Fi, etc.)? } \\
\text { - When patients are utilizing the device, do they encounter any communication issues? } \\
\text { - If yes, please elaborate. } \\
\text { - Are the training provided on ECUs sufficient and delivered appropriately? }\end{array}$ \\
\hline $\begin{array}{l}\text { Weaknesses } \\
\text { - Do patients face any obstacles when using the ECU? } \\
\text { - How is the patient affected when the ECU is not functioning properly? } \\
\text { - How long does it take you to repair and/or replace device? } \\
\text { - Are there any additional weaknesses you wish to identify regarding the } \\
\text { ECU device? }\end{array}$ & $\begin{array}{l}\text { Threats } \\
\text { - What obstacles do you face when providing patient education on ECUs? } \\
\text { - What obstacles do you face when receiving training on ECUs? } \\
\text { - Could changing technology threaten the functional capabilities of the device? } \\
\text { - Are there any additional threats you wish to identify regarding the ECU device? }\end{array}$ \\
\hline \multicolumn{2}{|l|}{-2} \\
\hline $\begin{array}{l}\text { Strengths } \\
\text { - What advantages do ECU devices bring to the facility? } \\
\text { - What benefits do ECUs provide to you? } \\
\text { - How much time, if any, have you spent receiving education on ECUs? } \\
\text { - Are there any additional strengths you wish to identify regarding the } \\
\text { ECU device? }\end{array}$ & $\begin{array}{l}\text { Opportunities } \\
\text { - How could the ECU be further improved? } \\
\text { - What interesting trends (patient satisfaction, impact on cost, etc.) are you aware of? } \\
\text { - How can the education on ECUs be improved? } \\
\text { - Wi-Fi, etc.)? } \\
\text { - When utilizing the device, do you encounter any communication issues? If yes, please } \\
\text { elaborate. } \\
\text { - Is the education provided on ECUs sufficient and delivered appropriately? } \\
\text { - Are there any additional opportunities you wish to identify regarding the ECU device? }\end{array}$ \\
\hline $\begin{array}{l}\text { Weaknesses } \\
\text { - Do you face any obstacles when using the ECU? } \\
\text { - How are you affected when the ECU is not functioning properly? } \\
\text { - Are there any additional weaknesses you wish to identify regarding the } \\
\text { ECU device? }\end{array}$ & $\begin{array}{l}\text { Threats } \\
\text { - What obstacles do you face when receiving education on ECUs? } \\
\text { - Are there any additional threats you wish to identify regarding the ECU device? }\end{array}$ \\
\hline \multicolumn{2}{|l|}{ Biomedical Engineer } \\
\hline $\begin{array}{l}\text { Strengths } \\
\text { - What advantages do ECU devices bring to the facility? } \\
\text { - What benefits do ECUs provide the patient? } \\
\text { - How much time, if any, do you spend educating patients on ECUs? } \\
\text { - How does patient customization affect the repairs/replacements of the } \\
\text { device? } \\
\text { - Are there any additional strength you wish to identify regarding the } \\
\text { ECU device? }\end{array}$ & $\begin{array}{l}\text { Opportunities } \\
\text { - How could the ECU be further improved? } \\
\text { - Are there any capabilities the ECU does not have, but could be added (i.e., phone, } \\
\text { Wi-Fi, etc.)? } \\
\text { - Are there any additional opportunities you wish to identify regarding the ECU device? }\end{array}$ \\
\hline $\begin{array}{l}\text { Weaknesses } \\
\text { - Do you face any obstacles when repairing/replacing ECUs? } \\
\text { - How long does it take you to repair and/or replace device? } \\
\text { - Are there any additional weaknesses you wish to identify regarding the } \\
\text { ECU device? }\end{array}$ & $\begin{array}{l}\text { Threats } \\
\text { - What obstacles do you face when replacing/repairing ECUs? } \\
\text { - Could changing technology threaten the functional capabilities of the device? } \\
\text { - Are there any additional threats you wish to identify regarding the ECU device? }\end{array}$ \\
\hline \multicolumn{2}{|l|}{ Environmental Management Services } \\
\hline$\frac{\text { Strengths }}{\text { - Are there any strengths you wish to identify regarding the ECU device? }}$ & $\frac{\text { Opportunities }}{\text { - Are there any opportunities you wish to identify regarding the ECU device? }}$ \\
\hline $\begin{array}{l}\text { Weaknesses } \\
\text { - Are there any weaknesses you wish to identify regarding the ECU } \\
\text { device? }\end{array}$ & $\begin{array}{l}\text { Threats } \\
\text { - What obstacles do you face when cleaning ECUs? } \\
\text { - Are there any threats you wish to identify regarding the ECU device? }\end{array}$ \\
\hline
\end{tabular}

\subsection{Data analysis}

Descriptive statistics were used to summarize the findings. Trend analysis for the elapsed time (process/task start and end) was also conducted. Interactions observed were grouped into two categories: Group 1 (ECU Malfunction) was when the ECU was not used due to troubleshooting, replacement, repair, and/or work order request, and Group 2 (ECU Assistance) was when the ECU was not used because of protocol to get it started (i.e., admission, patient education, set-up). Cross-tabulation was used to examine the relationship between each group by facility.

For the SWOT analyses, all responses were de-identified 
and assigned a random identification number to protect the integrity of the feedback. Three coders (TJ, RD, KT) individually read the initial responses multiple times and extracted major themes. The coders developed a codebook with themes and emerging themes. All the feedback text and the codebook were uploaded into NVIVO 10 software. Within NVIVO, each coder independently (but simultaneously) reviewed each response from each facility. They evaluated each line of text and attached codes to selected text that matched a theme in the codebook. Selected text could be marked by an unlimited number of codes if it was relevant to more than one theme. The codes to each response were merged, duplicative codes were collapsed into a single code, and unique codes across each of the coders were discussed and included in the merged file, if deemed relevant. The final results were compared for the three coders and reports of coding themes and frequencies were generated in NVIVO.

\section{RESUltS}

There were 59 observations of interactions with ECUs across the four facilities $(\min =11, \max =21$, mean $=14.5)$. Approximately two-thirds of the Veterans observed had paraplegic level injuries $(n=40,68 \%)$ and the remainder were tetraplegic $(n=19,32 \%)$. The majority of Veterans were between 50-60 years old $(n=22,49 \%)$. Eighty-nine percent ( $n=33$ ) of the waste observed was due to defect or rework (ECU Malfunction and ECU Assistance). Table 3 outlines the processes observed by demographics when the ECUs were not utilized: $71.2 \%(n=42)$ were due to ECU Malfunction (Group 1) and $28.8 \%(n=17)$ were due to ECU Assistance (Group 2).

Table 3. Descriptive statistics

\begin{tabular}{|c|c|c|c|c|c|c|c|c|c|}
\hline & & \multicolumn{4}{|c|}{ Group 1: ECU Malfunction } & \multicolumn{3}{|c|}{ Group 2: ECU Assistance } & \multirow{3}{*}{$\begin{array}{l}\text { Total } \\
\text { n/total (\%) }\end{array}$} \\
\hline & & \multirow{2}{*}{$\begin{array}{c}\text { Replacement } \\
\text { n/total (\%) }\end{array}$} & \multirow{2}{*}{$\begin{array}{l}\text { Troubleshooting } \\
\text { n/total (\%) }\end{array}$} & \multirow{2}{*}{$\begin{array}{l}\text { Repair } \\
\text { n/total (\%) }\end{array}$} & \multirow{2}{*}{$\begin{array}{l}\begin{array}{l}\text { Work order } \\
\text { request }\end{array} \\
\text { n/total }(\%) \\
\end{array}$} & \multirow{2}{*}{$\begin{array}{l}\text { Set-up } \\
\text { n/total (\%) }\end{array}$} & \multirow{2}{*}{$\begin{array}{l}\text { Admission } \\
\text { n/total (\%) }\end{array}$} & \multirow{2}{*}{\begin{tabular}{|l|}
$\begin{array}{l}\text { Patient } \\
\text { education }\end{array}$ \\
n/total (\%)
\end{tabular}} & \\
\hline & & & & & & & & & \\
\hline \multirow{4}{*}{ Facility } & Facility 1 & 2/3 (66.7\%) & $11 / 30(36.7 \%)$ & $1 / 7(14.3 \%)$ & $1 / 2(50.0 \%)$ & $0 / 5(0.0 \%)$ & $1 / 4(25.0 \%)$ & $5 / 8(62.5 \%)$ & $21 / 59$ (35.5\%) \\
\hline & Facility 2 & 1/3 (33.3\%) & 8/30 (26.7\%) & $0 / 7(0.0 \%)$ & $0 / 2(0.0 \%)$ & $0 / 5(0.0 \%)$ & 3/4 (75.0\%) & $0 / 8(0.0 \%)$ & $12 / 59(20.3 \%)$ \\
\hline & Facility 3 & $0 / 3(0.0 \%)$ & 7/30 (23.3\%) & $1 / 7(14.3 \%)$ & $1 / 2(50.0 \%)$ & $3 / 5(60.0 \%)$ & $0 / 4(0.0 \%)$ & $2 / 8(25.0 \%)$ & $14 / 59(23.7 \%)$ \\
\hline & Facility 4 & $0 / 3(0.0 \%)$ & 4/30 (13.3\%) & $5 / 7(71.4 \%)$ & $0 / 2(0.0 \%)$ & $2 / 5(40.0 \%)$ & $0 / 4(0.0 \%)$ & 1/8 (12.5\%) & $12 / 59(20.3 \%)$ \\
\hline \multirow{3}{*}{$\begin{array}{l}\text { Age } \\
\text { Group }\end{array}$} & $30-50$ yrs & $0 / 3(0.0 \%)$ & 2/21 (9.5\%) & $0 / 6(0.0 \%)$ & $0 / 2(0.0 \%)$ & 3/3 (100.0\%) & $0 / 4(0.0 \%)$ & $3 / 6(50.0 \%)$ & 8/45 (17.8\%) \\
\hline & $50-60$ yrs & 3/3 (100.0\%) & 13/21 (61.9\%) & 2/6 (33.3\%) & $1 / 2(50.0 \%)$ & $0 / 3(0.0 \%)$ & $1 / 4(25.0 \%)$ & $2 / 6(33.3 \%)$ & $22 / 45$ (48.9\%) \\
\hline & $60+\mathrm{yrs}$ & 0/3 (0.0\%) & 6/21 (28.6\%) & 4/6 (66.7\%) & $1 / 2(50.0 \%)$ & $0 / 3(0.0 \%)$ & 3/4 (75.0\%) & 1/6 (16.7\%) & 15/45 (33.3\%) \\
\hline \multirow{2}{*}{$\begin{array}{l}\text { Type of } \\
\text { Injury }\end{array}$} & Tetraplegic & 1/3 (33.3\%) & $12 / 30$ (40.0\%) & 2/7 (28.6\%) & $1 / 2(50.0 \%)$ & $0 / 5(0.0 \%)$ & $0 / 4(0.0 \%)$ & 3/8 (37.5\%) & 19/59 (32.2\%) \\
\hline & Paraplegic & 2/3 (66.7\%) & $18 / 30$ (60.0\%) & $5 / 7(71.4 \%)$ & $1 / 2(50.0 \%)$ & $5 / 5(100.0 \%)$ & $4 / 4(100.0 \%)$ & $5 / 8(62.5)$ & 40/59 (67.7\%) \\
\hline \multirow{3}{*}{ Waste } & Defect & $0 / 2(0.0 \%)$ & 26/28 (92.9\%) & $1 / 1(100.0 \%)$ & $1 / 1(100.0 \%)$ & $0(0.0 \%)$ & $0 / 4(0.0 \%)$ & $1 / 1(100.0 \%)$ & 29/37 (78.4\%) \\
\hline & $\begin{array}{l}\text { Not using } \\
\text { potential }\end{array}$ & $0 / 2(0.0 \%)$ & $0 / 28(0.0 \%)$ & $0 / 1(0.0 \%)$ & $0 / 1(0.0 \%)$ & $0(0.0 \%)$ & 4/4 (100.0\%) & $0 / 1(0.0 \%)$ & 4/37 (10.8\%) \\
\hline & Rework & 2/2 (100.0\%) & 2/28 (7.1\%) & $0 / 1(0.0 \%)$ & $0 / 1(0.0 \%)$ & $0(0.0 \%)$ & $0 / 4(0.0 \%)$ & $0 / 1(0.0 \%)$ & 4/37 (10.8\%) \\
\hline \multirow{3}{*}{$\begin{array}{l}\text { Person for } \\
\text { Support }\end{array}$} & $\begin{array}{l}\text { Biomedical } \\
\text { Engineer }\end{array}$ & 1/3 (33.3\%) & $11 / 30$ (36.7\%) & 2/7 (28.6\%) & $0 / 2(0.0 \%)$ & 5/5 (100.0\%) & $3 / 4(75.0 \%)$ & 1/8 (12.5\%) & $22 / 59$ (37.3\%) \\
\hline & $\begin{array}{l}\text { Nurse/Nursing } \\
\text { Assistant }\end{array}$ & $0 / 3(0.0 \%)$ & $1 / 30(3.3 \%)$ & 4/7 (57.1\%) & $0 / 2(0.0 \%)$ & $0 / 5$ (0.0\%) & $1 / 4(25.0 \%)$ & $0 / 8(0.0 \%)$ & 6/59 (10.1\%) \\
\hline & $\begin{array}{l}\text { Patient Experience } \\
\text { Liaison/Volunteer }\end{array}$ & 2/3 (66.7\%) & $18 / 30(60.0 \%)$ & 1/7 (14.3\%) & 2/2 (100.0\%) & $0 / 5(0.0 \%)$ & $0 / 4(0.0 \%)$ & 7/8 (87.5\%) & $30 / 59$ (50.8\%) \\
\hline \multirow{3}{*}{$\begin{array}{l}\text { Expected } \\
\text { Ease to } \\
\text { Correct }\end{array}$} & Easy & $0 / 2(0.0 \%)$ & $16 / 30$ (53.3\%) & 6/6 (100.0\%) & $0(0.0 \%)$ & 5/5 (100.0\%) & $0(0.0 \%)$ & 3/4 (75.0\%) & $30 / 47$ (63.8\%) \\
\hline & Medium & 2/2 (100.0\%) & 6/30 (20.0\%) & $0 / 6(0.0 \%)$ & $0(0.0 \%)$ & $0 / 5(0.0 \%)$ & $0(0.0 \%)$ & $0 / 4(0.0 \%)$ & 8/47 (17.0\%) \\
\hline & Hard & $0 / 2(0.0 \%)$ & 8/30 (26.7\%) & $0 / 6(0.0 \%)$ & $0(0.0 \%)$ & $0 / 5(0.0 \%)$ & $0(0.0 \%)$ & $1 / 4(25.0 \%)$ & 9/47 (19.1\%) \\
\hline \multirow{2}{*}{ Priority } & Medium & $0(0.0 \%)$ & $12 / 15(80.0 \%)$ & 1/6 (16.7\%) & 1/1 (100.0\%) & $0 / 5(0.0 \%)$ & $0(0.0 \%)$ & $1 / 4(25.0 \%)$ & 16/31 (51.6\%) \\
\hline & High & $0(0.0 \%)$ & 3/15 (20.0\%) & 5/6 (83.3\%) & $0 / 1(0.0 \%)$ & $5 / 5(100.0 \%)$ & $0(0.0 \%)$ & $3 / 4(75.0 \%)$ & 15/31 (48.4\%) \\
\hline
\end{tabular}

Fifty-one percent $(n=30)$ of observed staff interactions with the ECU were spent on troubleshooting which typically occurred prior to repairs and replacements. Troubleshooting accounted for approximately $13 \%-37 \%$ of the wasted time across all four facilities. They tended to require additional time, resources, or money to fix and were observed across

Published by Sciedu Press all age groups and among patients with both paraplegic and tetraplegic level injuries. For example, a problem may have been caused by an unplugged cord, which had a simple solution; however, the process to determine the solution took time to resolve. Fourteen percent $(n=8)$ of events involved patients receiving education on the ECU from a clinical staff 
member or patient experience liaison/volunteer. Twelve percent $(n=7)$ of the interactions were spent on some level of repair that was needed for the ECU to function properly. Repairs could usually be resolved within the same day. Eight percent $(n=5)$ of observed interactions were spent on setting up patients admitted to a SCI unit.

Sixty percent $(n=18)$ of the troubleshooting observations were supported by the patient experience liaison/volunteer, $37 \%(\mathrm{n}=11)$ were supported by the biomedical engineer, and $3 \%(n=1)$ were supported by the nurse/nursing assistant. Expected ease to correct the troubleshooting waste observed was as follows: $53 \%(n=16)$ were easy to correct in a short amount of time with little to no resources, and 47\% $(n=14)$ were considered either medium or hard to correct as they required long delays and/or additional resources. Eighty percent $(n=12)$ of troubleshooting issues were important to correct the identified waste but did not hinder the complete process flow and $20 \%(n=3)$ were essential to correct the identified issues for the process to flow and the ECU to function appropriately. The majority of patient education sessions were completed by a patient experience liaison/volunteer (n
$=7,87.5 \%)$ and the rest were completed by a biomedical engineer $(n=1,12.5 \%)$.

Based on 59 observations, Figure 2 summarizes elapsed time (in minutes) for each process/task. The elapsed time varied based on the process/task conducted (average $=21.9$, $\mathrm{min}$ $=1, \max =110, \mathrm{SD}=27.7$, mode $=10$, median $=12$ ). The majority of time was spent on 1) replacement of an ECU or needed parts $($ mean $=46.0)$ when simple repairs could not fix the ECU; 2) ECU set-up (mean = 36.8) for customization of an ECU based on patient needs, injury level, and mobility; 3) patient admittance to an SCI unit (mean = 35.0); and 4) troubleshooting $($ mean $=24.6)$. Troubleshooting typically occurred prior to repairs and replacements, however repairs and replacements were not always necessary. There was no significant difference in elapsed time between facility and Group 1 (ECU Malfunction) versus Group 2 (ECU Assistance). There was no significant difference between elapsed time spent in each group, by the four facilities, and by facility for ECU Malfunction. There was also no significant difference in the time spent on ECU Assistance by facility.

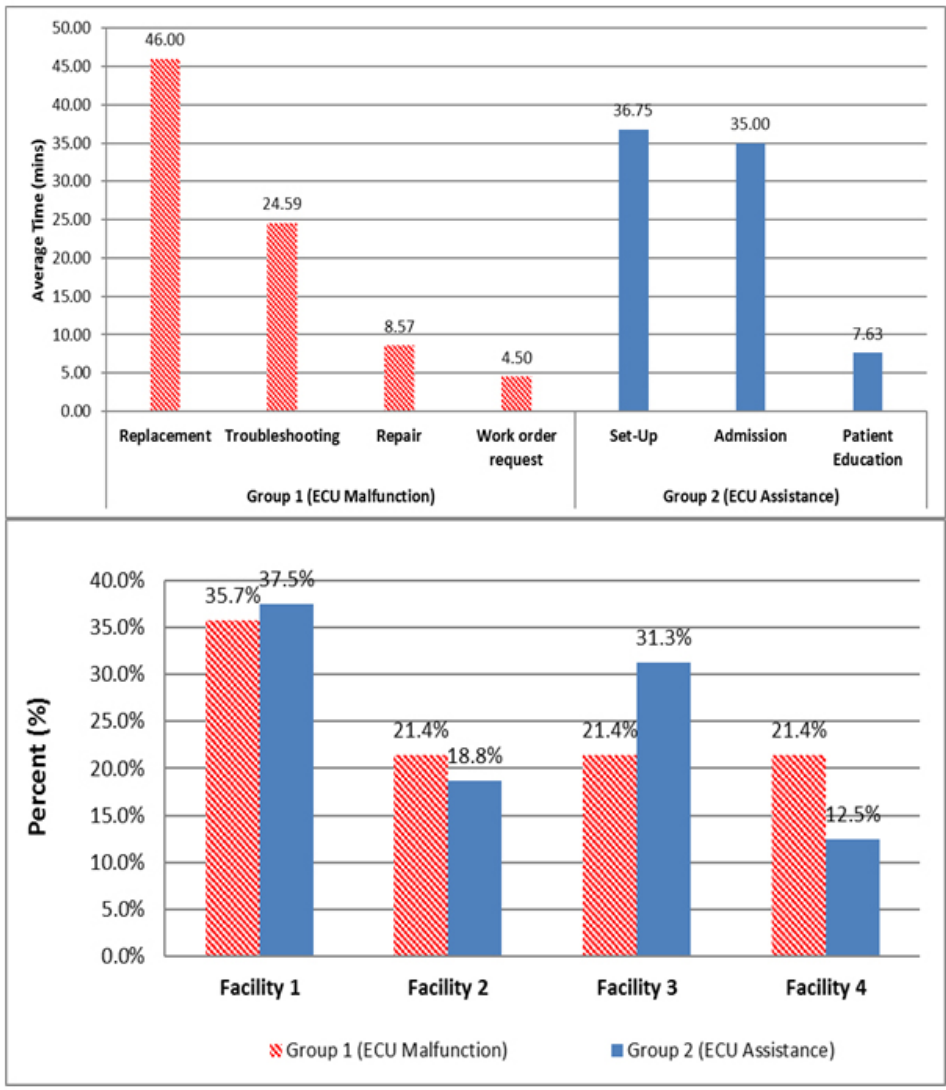

Figure 2. Time study analysis
Key:

- Admission: Patient admittance to a short-term or longterm care SCI unit. Also included initial patient education of the ECU.

- Patient Education: Patient received education on the ECU from a staff member or member of the SCI unit.

- Repair: Some level of the repair was needed in order for the ECU to function properly. Repairs could usually be resolved within the same day.

- Replacement: Replacement of an ECU or parts was needed when simple repairs could not fix the ECU. This process typically took more time than repairs to resolve.

- Set-Up: The customization of an ECU based on patient needs, injury diagnosis, and mobility.

- Troubleshooting: The systematic search for the source of a problem in order to solve it. Troubleshooting typically occurred prior to repairs and replacements, however repairs and replacements were not always necessary. For example, an unplugged cord may have been the solution to a problem.

- Work Order Request: The process that was completed when ordering additional supplies that were not in the facility inventory. 
Based on availability and willingness to participate across four facilities, 47 individuals participated in the SWOT analyses, garnering a total of 148 collected data points. Most of the participants were staff (Facility 1 included 7 staff and 6 Veterans; Facility 2 included 9 staff and 7 Veterans; Facility 3 included 11 staff and Facility 4 included 7 staff). The percentage breakdown was consistent within the individual facilities with $22 \%(\mathrm{n}=33)$ strengths, $37 \%(\mathrm{n}=55)$ weaknesses, $30 \%$ $(n=44)$ opportunities, and $11 \%(n=16)$ threats. Figure 3 illustrates the following six themes which represented $83 \%$ $(\mathrm{n}=123)$ of the distinct themes: usability $(\mathrm{n}=38,26 \%)$, compatibility $(n=32,22 \%)$, training $(n=21,14 \%)$, patient independence $(\mathrm{n}=12,8 \%)$, durability $(7 \%, \mathrm{n}=11)$, and interface $(n=9,6 \%)$.

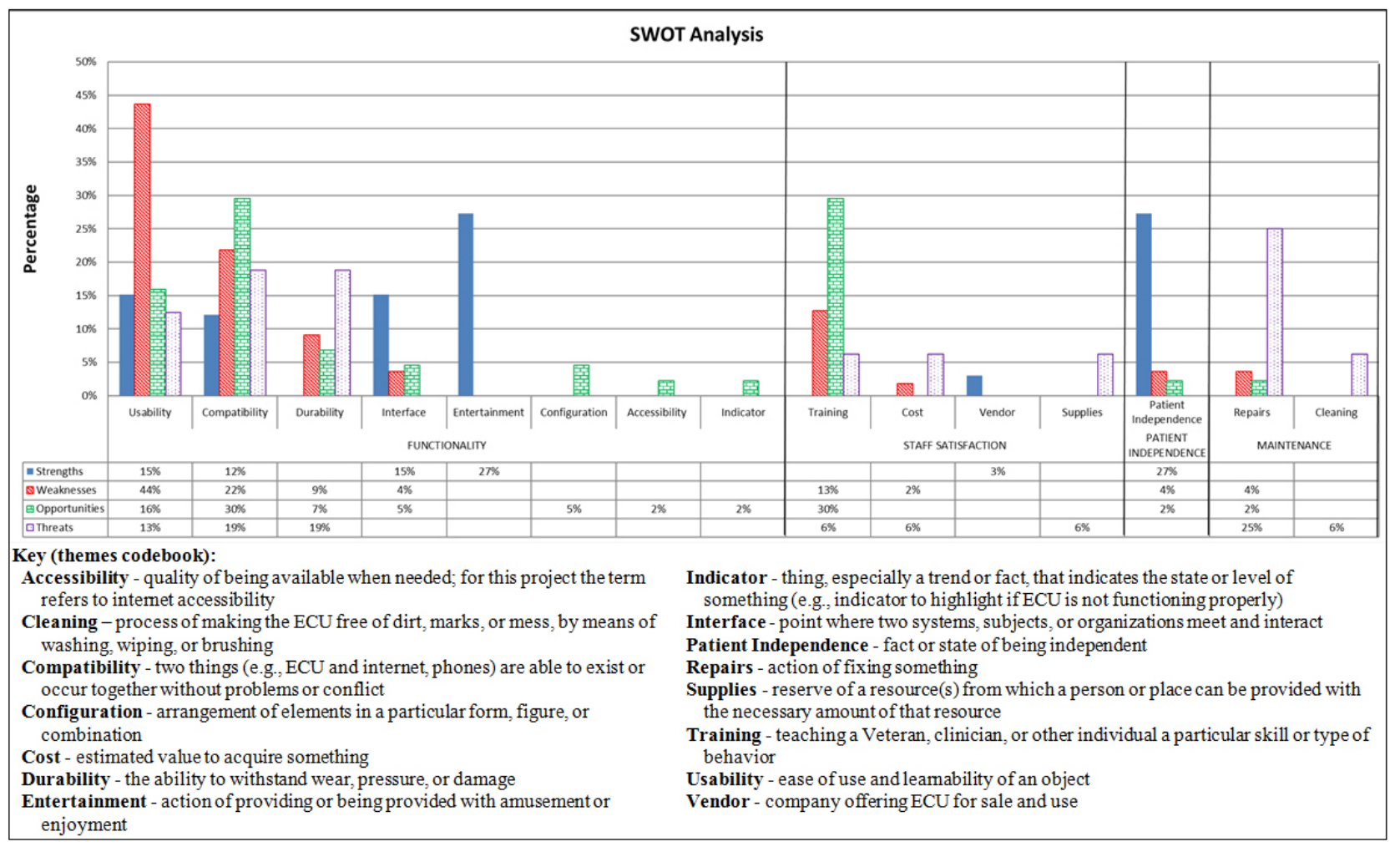

Figure 3. SWOT analysis and themes codebook

Seventy percent $(n=103)$ of the SWOT feedback provided insight on the users' perspectives on the functionality (i.e., human factors) of the ECU and $30 \%(n=45)$ on patient independence, patient and staff satisfaction, and maintenance. Seventy percent $(n=23)$ of the strengths were functionality (e.g., entertainment, usability, interface, compatibility) and $30 \%(\mathrm{n}=10)$ were patient independence and staff satisfaction. Weaknesses also were mostly functionality-related (e.g., usability, compatibility, durability, interface), which represented $78 \%(n=43)$ of the weaknesses. Opportunities were $66 \%(n=29)$ functionality (e.g., compatibility, usability, durability, configuration, interface, accessibility, indicator). Finally, threats were 50\% $(\mathrm{n}=8)$ functionality (e.g., durability, compatibility, usability), $19 \%(\mathrm{n}=3)$ staff satisfaction (e.g., cost, training, supplies) and $31 \%(\mathrm{n}=8)$ maintenance (e.g., repairs, cleaning).

Due to the limited mobility (functional limitations and/or disabilities), Veterans with SCI/D often have difficulty controlling their surroundings and tend to rely on others for assistance. In SCI Centers, when the ECU is malfunctioning, staff often spend a significant amount of time assisting Veterans with basic functions which reduces clinicians' time to provide clinical care to the patients. Table 4 summarizes the feedback outlining the benefits of a well-functioning ECU and the impact of ECU malfunctions for the following emerging themes: patient independence, delivery of patient care (clinician availability), patient safety, Veteran comfort level, Veteran and staff satisfaction. This supports how installation of additional ECUs could benefit SCI/D Veterans and staff in VAMCs across the United States.

When the ECUs were fully-functioning, the level of independence that patients gained from the ECUs varied across respondents. Based on the SWOT analyses, some Veterans spoke to the IEs about a level of independence in completing 
activities and engaging in leisurely hobbies. For example, it was described by one Veteran in acute care that "the ECU offers entertainment and the availability to stay in touch" with family members and by a Veteran with paraplegia who mentioned "enjoy[ing] Solitaire and... jump[ing] between applications". Another Veteran "appreciated [getting] on the internet [to] pay bills". Veterans also discussed the abil- ity to use the ECU to help control their surroundings and communicating with staff regarding their care. A paraplegic Veteran described "us[ing] the ECU quite a bit, especially for the TV and nurse call". A Veteran with tetraplegia spoke to the IE about "us[ing] the device to turn on the TV, use telephone, play Solitaire, and to control [the] room" such as the bed, lights, and blinds.

Table 4. Benefits of fully-functioning ECU and the impact/challenges of malfunctioning ECUs

\begin{tabular}{|c|c|c|}
\hline $\begin{array}{l}\text { Emerging } \\
\text { Themes }\end{array}$ & Benefits of Fully-Functioning ECU & $\begin{array}{l}\text { Impact/Challenges when ECU Malfunctions } \\
\text { (Group 1) }\end{array}$ \\
\hline $\begin{array}{l}\text { Patient } \\
\text { Independence }\end{array}$ & $\begin{array}{l}\text { Increased Veterans' independence to control aspects of their } \\
\text { environment (e.g., adjusting the bed, lights, blinds, changing } \\
\text { the television channel), participation in leisurely activities } \\
\text { (e.g., playing computer games, browsing the internet), and } \\
\text { keeping in touch with family (e.g., checking email, making a } \\
\text { phone call). } \\
\text { Increased patient independence may increase the availability } \\
\text { of nurses and other clinical staff to provide clinical care. }\end{array}$ & $\begin{array}{l}\text { Level of patient independence drops drastically } \\
\text { with some Veterans relying on staff to complete } \\
\text { simple tasks to control their environment. }\end{array}$ \\
\hline $\begin{array}{l}\text { Delivery of } \\
\text { Patient Care } \\
\text { (Clinician } \\
\text { availability) }\end{array}$ & $\begin{array}{l}\text { Staff members have more time to provide clinical care for } \\
\text { Veterans throughout the course of the day. }\end{array}$ & $\begin{array}{l}\text { Clinicians are often the first line of support for } \\
\text { troubleshooting errors with the ECUs, therefore, } \\
\text { workflows and the delivery of patient care may } \\
\text { be interrupted. Clinicians are not trained to solve } \\
\text { complex troubleshooting/set-up ECU issues, nor } \\
\text { are they content experts when it comes to ECU } \\
\text { repairs. Therefore, when clinicians spend } \\
\text { additional time troubleshooting the ECUs, less } \\
\text { time is spent on clinical care. }\end{array}$ \\
\hline Patient Safety & $\begin{array}{l}\text { Veterans feel safer as they report that the ECU allows them to } \\
\text { easily call the nursing staff for clinical care and/or assistance. }\end{array}$ & $\begin{array}{l}\text { Troubleshooting the ECU or spending time on } \\
\text { repairs/replacements may hinder the use of its } \\
\text { safety features. For instances, calls to a nurse } \\
\text { may take longer as an alternative method may } \\
\text { need to be utilized. }\end{array}$ \\
\hline $\begin{array}{l}\text { Patient } \\
\text { Comfort Level }\end{array}$ & $\begin{array}{l}\text { Improve the level of Veterans' comfort during their hospital } \\
\text { stay and allow for better care to and optimize the experience } \\
\text { with inpatient care for Veterans with SCI/D. } \\
\text { Veterans can easily improve their comfort level by turning on } \\
\text { and off the lights, moving the position of the bed, and } \\
\text { controlling the blinds. Furthermore, entertainment features } \\
\text { (e.g., games, TV) and social support features (e.g., email, } \\
\text { internet) provide a way for Veterans to spend their time while } \\
\text { in the hospital. }\end{array}$ & $\begin{array}{l}\text { Monotony may increase as many patients have } \\
\text { limited entertainment features (e.g., TV or radio), } \\
\text { reduced social support (e.g., rely on friend, } \\
\text { family, or staff visit). Additionally, being unable } \\
\text { to control the environment such as repositioning } \\
\text { the bed may cause the Veteran physical } \\
\text { discomfort. }\end{array}$ \\
\hline $\begin{array}{l}\text { Patient and } \\
\text { Staff } \\
\text { Satisfaction }\end{array}$ & $\begin{array}{l}\text { Veterans and staff mentioned the ECUs created a greater } \\
\text { level of patient independence, more options for } \\
\text { entertainment, and prevented repetitive routines and } \\
\text { monotony. Minimize the physical limitation challenges that } \\
\text { Veterans have when managing their environment. Increase } \\
\text { level of comfort and quality of care during hospital stays. } \\
\text { Ease to contact the clinical staff for patient safety needs. }\end{array}$ & $\begin{array}{l}\text { Veterans and staff who expressed dissatisfaction } \\
\text { with the ECUs reported many of the features } \\
\text { were not available or did not function properly } \\
\text { (e.g., usability, compatibility, durability, } \\
\text { interface) and/or needed unscheduled } \\
\text { maintenance (e.g., repairs, cleaning). }\end{array}$ \\
\hline
\end{tabular}


There were multiple instances when the ECUs needed to be replaced, repaired, and/or cleaned. Some obstacles when repairing/replacing ECUs involved the supply of replacements. Per one of the biomedical engineers, "there [was] not a large supply of replacement parts available". For example, at one SCI Center there were no extra replacement tabs, which are used to control the ECU. There were 37 ECUs installed but only 27 were in use since there were not enough of the replacement tabs. When the repairs involved technical issues that could not be handled by someone on-site, the team would call technical support provided by the ECU manufacturer. While this support team offered excellent service, it was not available after 6:00 p.m.

It was also observed that the ECUs in use were cleaned once or twice a week, usually when a patient was discharged or upon patient request. Training of the set-up and usage of the ECU and the training of the cleaning procedure of the ECU varied. An obstacle faced with cleaning the device was that there was no standardized cleaning system. Based on feedback from one of the environmental management services staff, the ECU "[wa]s only to be cleaned with alcohol wipes but staff [were] cleaning them with germicide wipes causing some of the screens to become damaged".

Table 5 summarizes the gap analysis from the 59 observations based on current challenges of the use of ECUs in SCI Center inpatient and long-term care units as well as the proposed solution approach for future PDSA QI cycles.

Table 5. Gap analysis - proposed solution approach

\begin{tabular}{|c|c|}
\hline Gap Analysis & Recommendation \\
\hline $\begin{array}{l}\text { Limited number of ECU experts on } \\
\text { site }\end{array}$ & $\begin{array}{l}\text { Create standardized education materials for patients and facility staff to improve the } \\
\text { usability and responsibility of the ECUs and reduce time spent resolving ECU complaints. } \\
\text { Implement service line agreements. During ECU roll-out, and on-going, ensure staffing } \\
\text { plans include biomedical engineers, patient experience liaisons, and/or volunteers trained to } \\
\text { support and troubleshoot the device so that effort by clinical staff on these tasks are } \\
\text { minimized. }\end{array}$ \\
\hline $\begin{array}{l}\text { Lack of understanding of ECU } \\
\text { sustainability }\end{array}$ & $\begin{array}{l}\text { Utilize a Sustain and Spread plan, a document which outlines how facilities will maintain } \\
\text { continued improvements and teach others how to implement them, to maintain the positive } \\
\text { benefits of the ECUs and continually build on them for the highest positive impact. }\end{array}$ \\
\hline $\begin{array}{l}\text { Lack of knowledge on } \\
\text { compatibility with technology } \\
\text { upgrades }\end{array}$ & $\begin{array}{l}\text { Schedule on-going formal educational sessions with manufacturers and routine training for } \\
\text { patients and staff to stay up-to-date with devices. }\end{array}$ \\
\hline $\begin{array}{l}\text { Do not know facility maintenance } \\
\text { of ECUs (e.g., training costs due to } \\
\text { staff turnover, training for } \\
\text { technology upgrades); lack of } \\
\text { understanding of ECU durability } \\
\text { (e.g., repair and replacement) }\end{array}$ & $\begin{array}{l}\text { Research maintenance costs (training, repair/replacement) to accurately budget for optimal } \\
\text { support of ECUs in the future. Inter-professional consultation with Infection Control } \\
\text { personnel regarding ECU, as a re-usable patient care equipment (PCE) that requires } \\
\text { specialized cleaning between patients following the manufacturer's “Instructions for Use } \\
\text { (IFU)” to mitigate breakdown of the ECU's surface areas, as well as infection prevention of } \\
\text { medical devices in accordance with hospital regulatory agencies (i.e., Joint Commission). }\end{array}$ \\
\hline
\end{tabular}

Four main challenges reported were 1) customization of the ECU to the individual patient which could be time consuming, 2) limited capability of the eye gaze and halo features, 3) limited access to internet (e.g., some facilities did not provide complimentary wireless internet), and 4) limited number of ECU experts at the facility to provide technical support in a timely manner to reduce downtime. Additionally, many of the facilities did not have detailed service line agreements outlining which service was responsible for providing maintenance, education, or troubleshooting efforts for the ECUs. This lack of understanding led to many unresolved complaints and frustration among staff and Veterans.
For instance, the initial complaint respondent may not have been knowledgeable to resolve an issue with the ECU and therefore an additional person had to be called to assist.

\section{Discussion}

While general satisfaction with the ECUs was mixed, the majority of Veterans and staff were satisfied by the added value from a fully-functioning ECU. Veterans who liked using the ECU complimented many of the features available including the internet, phone, and games, and some Veterans and staff mentioned the ECUs created a greater level of patient independence and prevented repetitive routines and monotony. 
The Veterans and staff who expressed dissatisfaction with the ECUs reported many of the features were not available or did not function properly. Additionally, some Veterans were not interested in using the ECUs because they felt that they did not have the level of technological skills required to operate them. Patients with SCI/D reported that the ECU tended to minimize the physical limitation challenges that they have by helping them to manage their environment and by providing a level of comfort during hospital stays. Also, Veterans felt safer because the ECU allowed them to easily call the nursing staff for clinical care and/or assistance. When the biomedical engineers and patient experience liaisons/volunteers assisted the patients with processes such as troubleshooting and set-up, nurses/nursing assistants tended to have more time to provide clinical care.

\section{Limitations}

Spending approximately five days to conduct the time studies and SWOT analyses was sufficient to conduct our evaluation but it did not provide us with sufficient time to collect enough data to have a large sample size to report statistically significant comparisons. Also, more time prior to site visits is recommended to allow the IEs to conduct some pre-work (e.g., map the "As-Is" state) prior to the on-site observations and evaluations. Additionally, time should be reserved for following up on missing data. Due to a lack of standard processes at each facility, it was often difficult to observe every interaction regarding the ECUs. Many of the interactions arose when staff members were on daily rounds and Veterans presented the individual with a question or complaint.

\section{Conclusion}

The results in this study supported the finding in the literature that Veterans with SCI/D are challenged to control their surroundings due to limited mobility (functional limitations and/or disabilities) and nurses and staff often spend a significant amount of time assisting these patients with basic functions which limits their time to provide clinical care. Additional supporting findings are that the ECU increases patience independence to control aspects of their environment and participation in activities. The increased patient independence may increase the availability of nurses and other clinical staff to provide clinical care and improve patient safety by allowing patients to easily call the nursing staff for assistance. Fully functioning ECUs tend to improve the level of a patient's comfort during their hospital stay, increase their general satisfaction with care, and allow for better care to and optimize the experience with inpatient care for Veterans with SCI/D.

The biggest insights from the evaluation at each site were
1) the lack of standardized training for Veterans and staff on the use and maintenance of the ECUs and 2) the need for trained dedicated non-clinical staff (patient volunteers or biomedical engineers) to support non-functioning ECUs to increase the clinician's available time for patient care. Although some staff members did receive training, changes and updates to the ECUs far outpaced the education received. The SWOT analysis revealed several strengths related to the ECUs. These strengths can be spread by actively dispersing best practices and knowledge through QI efforts and implementing these efforts in SCI Centers. By doing this, the best care and experience for Veterans with SCI/D can continue to be provided throughout the VA.

\section{Recommendations}

Based on the findings from our evaluation and gap analysis, the following recommendations are suggested for those who wish to implement ECUs at their facilities:

(1) Create standardized education materials for patients and facility staff to improve the usability and responsibility of the ECUs and reduce time spent resolving ECU complaints.

(2) Schedule on-going formal educational sessions with manufacturers and routine training for patients and staff to stay up-to-date with devices.

(3) Research maintenance costs (e.g., training, repair/replacement) to accurately budget for optimal support of ECUs in the future.

(4) Create detailed service line agreements outlining which service is responsible for providing maintenance, education, and/or troubleshooting efforts for the ECUs.

(5) During ECU roll-out, and on-going, ensure staffing plans include non-clinical staff such as biomedical engineers and patient experience liaisons/volunteers who are trained to support and troubleshoot the ECU so that effort by clinical staff on these tasks is minimized.

(6) Utilize a Sustain and Spread plan, a document which outlines how facilities will maintain continued improvements and teach others how to implement them, to maintain the positive benefits of the ECUs and continually build on them for the highest positive impact.

(7) Consultation with Infection Control to ensure specialized cleaning is enforced to mitigate breakdown of ECU surface areas and maintain infection prevention.

\section{FUNDING}

This work was supported by the VHA Innovation Program, US Department of Veterans Affairs. The views expressed in this article are those of the authors and do not necessarily 
represent the views of the Department of Veterans Affairs or the United States government.

\section{ACKNOWLEDGements}

The authors would like to thank Kristopher Teague, Innovation Coordinator, VHA Innovation Program, for his input in the question development, facilitation with gaining access to SCI Centers, and staff for data collection. Thanks to Kristen Tingley, Theadora James, and Ryan Dendinger, CPHT VACASE VERC industrial engineers, for conducting the on-site workflow evaluations and serving as coders for the SWOT analysis. Additional thanks to Ryan Dendinger for leading the on-site evaluations. CPHT would like to thank Amanda Kovach for her assistance in editing this manuscript.

\section{CONFLICTS OF INTEREST Disclosure}

The authors are employed full time by the Department of Veterans Affairs. All authors have declared no potential conflicts of interests with respect to the authorship, research and commercial value of publishing this article. The views expressed within are solely those of the authors and do not necessarily represent the views of the Department of Veterans Affairs or the United States government.

\section{REFERENCES}

[1] Cohen JT, Marino RJ, Sacco P, et al. Association between the functional independence measure following spinal cord injury and longterm outcomes. Spinal Cord. 2012 Oct 1; 50(10): 728-33. PMid: 22641254. https://doi.org/10.1038/sc. 2012.50

[2] U.S. Department of Veterans Affairs. Spinal Cord Injuries and Disorders System of Care. [Online].; 2017 [cited 2017 July 11.] Available from: https://www.sci.va.gov/VAs_SCID_System_of_Care .asp

[3] Barry W, St. Andre JR, Evans CT, S et al. Hypertension and antihypertensive treatment in veterans with spinal cord injury and disorders. Spinal Cord. 2013 Feb 1; 51(2): 109-15. PMid: 23147130. https://doi.org/10.1038/sc.2012.122

[4] St. Andre J, Smith B, Stroupe K, et al. A comparison of costs and health care utilization for veterans with traumatic and nontraumatic spinal cord injury. Top Spinal Cord Inj Rehab. 2011 Apr 1; 16(4): 27-42. https://doi.org/10.1310/sci1604-27

[5] Tzonichaki L, Kleftaras G. Paraplegia from spinal cord injury: Selfesteem, loneliness, and life satisfaction. OTJR. 2002 Jul 1; 22(3): 96-103. https://doi.org/10.1177/153944920202200302

[6] Taylor-Schroeder S, LaBarbera J, McDowell S, et al. The SCIRehab project: treatment time spent in SCI rehabilitation. Physical therapy treatment time during inpatient spinal cord injury rehabilitation. J Spinal Cord Med. 2010 Dec 1; 34(2): 149-161. PMid: 21675354. https ://doi.org/10.1179/107902611X12971826988057

[7] Ozelie R, Sipple C, Foy T, et al. SCIRehab Project series: the occupational therapy taxonomy. J. Spinal Cord Med. 2009 Jun 1; 32(3): 283-97. PMid: 19810630. https://doi.org/10.1080/107902 68.2009 .11760782

[8] Langley GL, Moen R, Nolan KM, et al. The improvement guide: A practical approach to enhancing organizational performance. 2nd ed. San Francisco: Jossey-Bass Publishers; 2009.

[9] Anderson JC, Rungtusanatham M, Schoeder RG. A theory of quality management underlying the Deming management method. Academic Management Review. 1994; 19(3): 472-509.

[10] U.S. Department of Veterans Affairs. Mission, Vision, Core Values \& Goals. [Online] 2015. Available from: http://www.va.gov/a bout_va/mission.asp

[11] Zidel T. A lean guide to transforming healthcare: How to implement lean principles in hospitals, medical offices, clinics, and other healthcare organizations Milwaukee: ASQ Quality Press; 2006 Sep 1.

Published by Sciedu Press
[12] Gordon J, Hazlett C, Ten Cate O, et al. Strategic planning in medical education: enhancing the learning environment for students in clinical settings. Medical Education. 2000 Oct 5; 34(10): 84150. PMid: 11012934. https ://doi.org/10.1046/j.1365-292 3.2000.00759. $\mathrm{x}$

[13] Pearce C. Ten steps to carrying out a SWOT analysis: Chris Pearce offers a guide to help nursing leaders analyse their activities. Nursing Management. 2007 May 1; 14(2): 25-25. https ://doi.org/10.7 $748 / \mathrm{nm} 2007.05 .14 .2 .25 . \mathrm{c} 4343$

[14] Lamontagne ME, Swaine BR, Lavoie A, et al. Analysis of the strengths, weaknesses, opportunities and threats of the network form of organization of traumatic brain injury service delivery systems. Brain Inj. 2011 Nov 1; 25(12): 1188-97. PMid: 21939374 https://doi.org/10.3109/02699052.2011.608211

[15] Camden C, Swaine B, Tétreault S, et al. SWOT analysis of a pediatric rehabilitation programme: a participatory evaluation fostering quality improvement. Disabil Rehabil. 2009 Jan 1; 31: 1373-81. PMid: 19294544. https://doi.org/10.1080/09638280802532696

[16] Sharma M, Bhatia G. The voluntary community health movement in India: a strengths, weaknesses, opportunities, and threats (SWOT) analysis. Journal of Community Health. 1996 Dec 1; 21(6): 453-64. PMid: 8912121. https://doi.org/10.1007/BF01702605

[17] Toivanen T, Lahti S, Leino-Kilpi H. Applicability of SWOT analysis for measuring quality of public oral health services as perceived by adult patients in Finland: Strengths, weaknesses, opportunities and threats. Community Dentistry and Ora. Community Dent Oral. 1999 Oct 1; 27(5): 386-391. https://doi.org/10.1111/j.1600-0 528.1999.tb02035.x

[18] Mann NC, MacKenzie E, Teitelbaum SD, et al. Trauma system structure and viability in the current healthcare environment: A state-bystate assessment. The Journal of TRAUMA Injury, Infection, and Critical Care. 2005; 58: 136-147. https ://doi.org/10.1097/01 .TA.0000151181.44658.0A

[19] Williams CM, Petrelli J, Murphy M. Development and implementation of a geriatric care/case management program in a military community-based family medicine residency. Mil Med. 2000 Nov 1; 165(11): 809-15. PMid: 11143424.

[20] Freivalds A, Niebel BW. Niebel's methods, standards, and work design. 12th ed. New York: The McGraw-Hill Companies; 2009.

[21] Nash MA, Poling SR. Mapping the total value stream New York: Taylor \& Francis Group; 2008.

[22] Womack JP, Jones DT. Lean Thinking. 2nd ed. New York: Simon \& Schuster, Inc.; 2003. 